\title{
The Fate of Von Willebrand Factor Concentrate During Cardiopulmonary Bypass: A Case Report
}

\author{
Jaime L Bozentka, Brandon E Cowan, Madelyn D Kahana and Heidi M Boules* \\ Department of Anesthesiology, Montefiore Medical Center/Albert Einstein School of Medicine, United States
}

Submission: January 28, 2019; Published: February 25, 2019

*Corresponding author: Heidi Boules, Department of Clinical Anesthesiology, Yale School of Medicine, 25-21 43rd Ave \#806Long Island City, NY 11101, United States

\begin{abstract}
Management of coagulation in patients with von Willebrand Disease (VWD) during Cardiopulmonary Bypass (CPB) is made feasible by the availability of human plasma-derived factor VIII/von Willebrand factor complex concentrates (HPD-FVIII/VWF). Literature supports management using these factors, however their pharmacokinetic properties during CPB remain unknown. We measured the levels and activity of von Willebrand factor during mitral valve replacement of a 16-year-old female with symptomatic VWD. Our findings provide novel evidence that HPD-FVIII/VWF remains in circulation and active after exposure to the CPB circuit. This supports the efficacy of HPD-FVIII/VWF for hemostasis during CPB in patients with VWD.
\end{abstract}

Keywords: Coagulation; Cardiopulmonary; Patients; Surgical; Blood; Antigen; Infusion; Annuloplasty; Anesthesia

\section{Introduction}

Patients with von Willebrand Disease present a unique challenge to the management of coagulation during the perioperative period. The lack of functional von Willebrand Factor (VWF) and resultant platelet dysfunction increases the risk of surgical blood loss. This risk is amplified in surgeries requiring cardiopulmonary bypass -- a procedure which causes its own inherent coagulopathy. In order to mitigate these risks, plasma levels of VWF are repleted using exogenous factor concentrates. VWF replacement therapy is available as human plasma-derived factor VIII/VWF complex concentrates (HPD-FVIII/VWF). Monitoring of HPDFVIII/VWF therapy is achieved through following blood levels (via
VWF antigen) and activity (via VWF ristocetin cofactor assay) of VWF, with a therapeutic target level (>100 IU/dL) being similar to normal ranges.

Several case reports have demonstrated the successful management of patients with VWD undergoing surgery with CPB with the use of HPD-FVIII/VWF [1,2]. What has yet to be described is whether these factors behave similarly to endogenous factors when subjected to the CPB circuit. This case attempts to address this lack of data in the field by quantifying VWF levels and activity during CPB.

Description of the Case

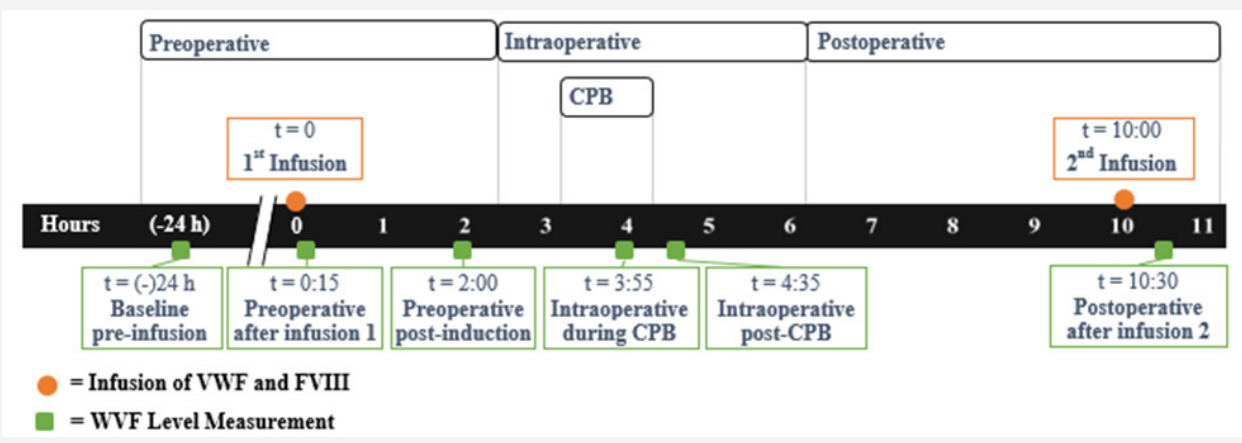

Figure 1: Timeline of recombinant von Willebrand factor (VWF) and Factor VIII (FVIII) infusions in respect to perioperative course and serum assays. Time (t) is in hour (h) and minute format. Pre-infusion assay was taken on day before operation. 


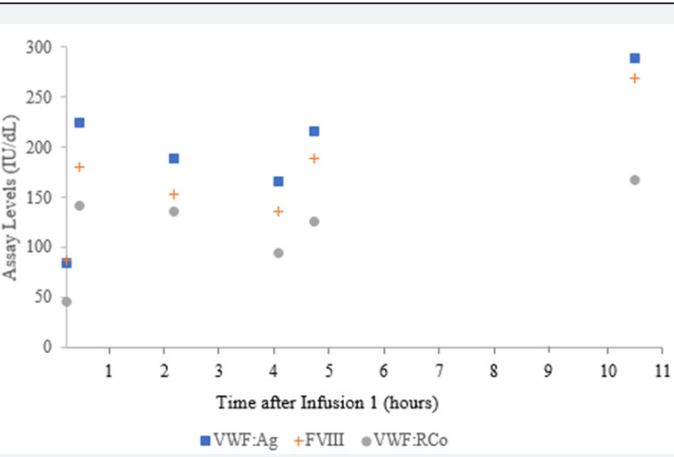

Figure 2: Serum levels of von Willebrand Factor antigen (VWF:Ag), Factor VIII coagulation assay, and von Willebrand ristocetin cofactor activity levels, as measured at various timepoints in the perioperative period. Timepoint 0 represents baseline levels measured on previous day.

A 16-year-old female with history of VWD type 2M and rheumatic fever presented for surgical repair of mitral valve insuffi ciency. Preoperative evaluation yielded a history of menorrhagia and anemia, with blood work revealing decreased VWF activity (Table 1; Baseline, Pre-infusion) -- all signifying symptomatic VWD. Pediatric hematology was consulted and suggested HPDFVIII/VWF (60 IU/kg) be given one hour prior to the operation, with an additional dose planned postoperatively. We sent blood samples for VWF levels and activity on a predetermined schedule which can be seen in the Figure $1 \& 2$. As is recommended, VWF activity, FVIII levels, and VWF antigen levels greater than $100 \mathrm{IU} /$ dL were achieved prior to surgery (Table 1; After Infusion \#1).

Table 1: Von Willebrand Assays. Levels of all factors rose after infusion of exogenous human plasma-derived factor VIII/von Willebrand factor complex concentrates. Due to the dilution involved in the cardiopulmonary bypass circuit, levels drop during bypass. Levels rose again after bypass, and once more after an additional post-operative infusion. Legend: VWF: Ag = VWF antigen level (normally 50-200); VWF: Rco = VWF ristocetin cofactor activity level (normally 50-200); FVIII = facteor VIII coagulation assay (normally 100); CPB = cardiopulmonary bypass.

\begin{tabular}{|c|c|c|c|c|c|c|}
\hline \multirow[b]{2}{*}{ Assay } & \multicolumn{3}{|c|}{ Preoperative } & \multicolumn{2}{|c|}{ Intraoperative } & \multirow{2}{*}{$\begin{array}{c}\begin{array}{c}\text { Post- } \\
\text { oper- } \\
\text { ative }\end{array} \\
\begin{array}{c}\text { After } \\
2^{\text {nd }} \\
\text { Infu- } \\
\text { sion }\end{array}\end{array}$} \\
\hline & $\begin{array}{l}\text { Base- } \\
\text { line, } \\
\text { Pre-In- } \\
\text { fusion }\end{array}$ & $\begin{array}{c}\text { After } \\
\mathbf{1}^{\text {st }} \text { Infu- } \\
\text { sion }\end{array}$ & $\begin{array}{l}\text { Post-In- } \\
\text { duction }\end{array}$ & $\begin{array}{c}\text { During } \\
\text { CPB }\end{array}$ & $\begin{array}{c}\text { Post- } \\
\text { CPB }\end{array}$ & \\
\hline $\begin{array}{c}\text { VWF:Ag } \\
\text { (IU/ } \\
\text { dL) }\end{array}$ & 84 & 225 & 188 & 166 & 216 & 289 \\
\hline $\begin{array}{l}\text { VWF:R- } \\
\text { Co (IU/ } \\
\text { dL) }\end{array}$ & 45 & 141 & 135 & 94 & 126 & 167 \\
\hline $\begin{array}{c}\text { FVIII } \\
\text { (IU/ } \\
\text { dL) }\end{array}$ & 87 & 180 & 153 & 136 & 189 & 269 \\
\hline
\end{tabular}

The patient was taken to the operating room and underwent an uneventful physio ring mitral annuloplasty under general anesthesia. Aminocaproic acid bolus and infusion were used. Heparin was used for anticoagulation prior to the start of CPB. The total bypass time was sixty minutes with a cross clamp time of forty minutes. A decline in all measures of VWF was observed during CPB (Table 1; During CPB). Post-bypass protamine was used for heparin reversal. Immediately after separation from CPB, all measured parameters returned to near pre-bypass concentrations (Table 1; Post-CPB). Hemostasis was easily obtained, not requiring transfusion of any blood products. Postoperatively she was taken to the pediatric intensive care unit. She received the planned additional dose of factor concentrate, resulting in a further increase in factor levels (Table 1; Postoperative). She had an uncomplicated hospital course, not requiring transfusion of blood products for the duration of her admission. On postoperative day five she was discharged home.

\section{Discussion}

\section{Von Willebrand Disease}

Von Willebrand Disease is the most common hereditary blood clotting disorder. Symptoms include epistaxis, menorrhagia, bleeding during and after surgery, and easy bruising. VWD disrupts platelet function as a result of a deficiency or dysfunction of VWF. VWF is essential to the recruitment of circulating platelets during vascular injury, as it provides a means of adherence to the vessel endothelium as well as platelet-to-platelet aggregation. Additionally, VWF stabilizes coagulation FVIII from rapid degradation [3].

There are three types of congenital VWD. Type 1 is caused by a missense mutation resulting in a quantitative deficit and is usually associated with mild disease. Type 2 is a group of qualitative defects where VWF is expressed in normal amounts, but missense mutations lead to defective multimer assembly. Type 2 disease is associated with mild to moderate bleeding [3]. Of particular interest to this case, type $2 \mathrm{M}$ causes poor binding to the platelet receptor glycoprotein Ib [4] Type 3, the most severe, is a complete absence of VWF.

An acquired form of von Willebrand disease also exists and is relatively rare. The pathogenesis is not well understood but involves autoantibodies to VWF, leading to clearance of VWF from circulation. Typically, acquired VWD presents in elderly patients without personal or family history of bleeding disorders and a presence of an autoimmune or hemato proliferative disorder [5].

Measurement of VWF in human plasma requires both quantitative measurement as well as evaluation of VWF activity. Von Willebrand ristocetin cofactor assay (VWF: RCo) measures function of VWF; VWF: Ag is an immunoassay measuring quantity of VWF, and the FVIII coagulant assay reflects the ability of VWF to bind FVIII in plasma. All are measured in IU/dL with a value of 50-200 being normal [6]. These assays can be used to monitor therapy; however, levels have never before been reported during $\mathrm{CPB}$. These assays can be used to monitor therapy, as was done in our case. 


\section{VWD Treatment}

There are three therapeutic strategies employed to prevent or control bleeding in VWD, which are to induce greater release of $\mathrm{VWF}$, to administer replacement VWF, or to otherwise augment the response to bleeding. Clinical decisions between the therapies depend on the type of disease and the severity of the bleeding encountered.

Desmopressin is commonly used to control bleeding in VWD type 1. It induces release of VWF stored in endothelial cells, making it most effective in the setting of mild quantitative VWF defects. When desmopressin is used as prophylactic treatment for minor surgeries and in bleeding, target VWF: RCo levels of at least $30 \mathrm{IU} / \mathrm{dL}$ and preferably $>50 \mathrm{IU} / \mathrm{dL}$ are recommended [6]. Desmopressin is ineffective for the treatment of qualitative defects found in patients with VWD type 2 as well as the complete absence of VWF in patients with VWD type $3[4,7,8]$. A limitation of this therapy is the diminished response to repeated doses due to depletion of stored VWF [6].

FVIII/VWF-complex replacement therapy is the definitive treatment for VWD and is the focus of this case review. HPD-FVIII/ VWF concentrates are processed from human plasma to inactivate viruses and prions and were developed as a safer alternative to cryoprecipitate [8]. Guidelines suggest using factor concentrate replacement therapy for significant bleeding or major surgery, or when the patient is refractory to other treatments. HPD-FVIII/ VWF complex concentrates are available for intravenous administration to increase levels of VWF perioperatively [8]. It is recommended to achieve VWF: RCo levels of at least $100 \mathrm{IU} / \mathrm{dL}$ is to achieve optimal perioperative coagulation for major surgery [6].

While not directly addressing VWF, various adjuvant therapies may be used perioperatively to promote hemostasis in these patients. Aminocaproic acid and tranexamic acid are IV or oral agents that stabilize clots by preventing fibrinolysis. Topical bovine thrombin, fibrin sealants, and collagen sponges are approved to treat mucocutaneous bleeding. Topical agents may be viewed as optional adjunctive therapy for VWD [6].

\section{Coagulopathy in Cardiopulmonary Bypass}

The coagulopathy that occurs during cardiopulmonary bypass is multifactorial. Hemodilution is a significant consequence of CPB that affects coagulation factor levels [9]. All CPB circuits are primed with fluid which may be composed of crystalloid solution, colloid solution, packed red blood cells, or a mixture of these components [10]. Hemodilution carries the consequences of limiting oxygen availability, changing viscosity and oncotic pressure, and diluting immunoglobulins [10]. Importantly, the effective increased volume of distribution when the patient's blood volume is mixed with the CPB circuit priming solution decreases coagulation factor levels leading to clinically significant post-bypass bleeding $[11,12]$. Just as the patient's native coagulation factors are exposed to dilution by the priming volume, one would expect the prepared factor concentrates the are supplemented prior to CPB would also undergo dilution.

A second contributor to coagulation defects during CPB is a consumptive coagulopathy. This is initiated by the patient's blood coming into contact with the synthetic surface of the CPB circuit. Inflammation and coagulation then ensue with a resultant consumption of coagulation factors. The degree of loss of coagulation factors is dependent upon the length of time blood is exposed to the bypass circuit. This coagulation is suppressed to the fullest extent possible with heparin, but some coagulation factors are still incidentally consumed during CPB [13].

\section{Case Findings}

As described in the details of the case, coagulation factor levels and activity decline by $25-34 \%$ from baseline during CPB. The observed descent can be explained in large part by the dilutional effects previously discussed. Across the literature, studies demonstrate losses of $30-40 \%$ in the same time period in patients with normal coagulation phenotypes [14]. Therefore, we observed a lesser degree of decline in the measured factor levels during this case than is typically encountered. This may be due to exaggerated baseline factor levels in our patient after administration of exogenous concentrate or possibly due to prolonged factor life inherent to the exogenous preparation. More likely though, in a true prospective study which is adequately powered, this difference may disappear.

Additionally, the total time on bypass in this case was relatively brief, therefore consumption of factors including those which were administered to the patient for the treatment of her VWD was probably negligible. Coagulation factor activity and levels could vary depending on the time on bypass, but the extent of variation is unknown to us after studying only one case.

\section{Conclusion}

This case presents an important addition to the current literature in confirming that factor concentrations and activity levels in this patient were affected by CPB in a way that is similar to patients without VWD. We describe the successful management of a patient with VWD for cardiac surgery. Moreover, by quantifying factor activity and factor levels we provide direct evidence of the pharmacokinetic properties of administered human plasma-derived factor VIII/VWF complex concentrates during CPB, which has never been previously reported.

This manuscript adheres to the CARE Case Report Guidelines.

\section{References}

1. Teppone Martin OL, Zhao M, Norris T (2013) Von Willebrand Disease and Cardiopulmonary Bypass. AANA Journal 81(1): 60-64.

2. Gerling V, Lahpor JR, Buhre W (2007) Peri-operative management of an adult patient with type $2 \mathrm{~N}$ von Willebrand's disease scheduled for coronary artery bypass graft. Anaesthesia 62(4): 405-408. 
3. Kumar V, Abbas AK, Aster JC (2015) Robbins and Cotran Pathologic Basis of Disease. ( $9^{\text {th }}$ Edn), PA: Elsevier/Saunders, Philadelphia, p. 1408.

4. James PD, Goodeve AC (2011) Von Willebrand Disease. Genetics in medicine 13(5): 365-376.

5. Shaji Kumar, Rajiv K Pruthi, William L Nichols (2002) Acquired von Willebrand Disease, Mayo Clinic Proceedings 77(2): 181-187.

6. (2007) The Diagnosis, Evaluation, and Management of von Willebrand Disease. National Heart, Lung, and Blood Institute.

7. Buga Corbu I, Arion C (2014) Up to date concepts about Von Willebrand disease and the diagnose of this hemostatic disorder. Journal of Medicine and Life 7(3): 327-334.

8. Harper P, Favaloro EJ, Curtin J, Barnes C, Dunkley S (2016) Human plasma-derived FVIII/VWD concentrate (Biostate): a review of experimental and clinical pharmacokinetic, efficacy and safety data. Drugs Context 5: 212292

9. Timothy S Hall (1995) The Pathophysiology of Cardiopulmonary Bypass. Chest 107(4): 1125-1133.
10. Jonas R (2014) Comprehensive Surgical Management of Congenital Heart Disease. (1 ${ }^{\text {st }}$ Edn), London, USA, pp. 117-150.

11. Bull BS, Hay KL, Herrmann PC (2009) Postoperative bypass bleeding: a bypass-associated dilutional (BAD) coagulopathy? Blood Cells Mol Dis 43(3): 256-259.

12. Hall RI, Kent B (2008) Changes in the pharmacokinetics and pharmacodynamics of drugs administered during cardiopulmonary bypass. In: Gravlee GP, Davis RF, Stammers AH, Ungerleider RM (Eds.), Cardiopulmonary bypass, ( $3^{\text {rd }}$ Edn), PA: Lippincott Williams \& Wilkins, Philadelphia, pp. 190-260.

13. Odonkor P, Archana Srinivas, Erik Strauss (2017) Perioperative Coagulation Management of a Hemophilia A Patient During Cardiac Surgery. Seminars in cardiothoracic and vascular anesthesia 21(4): 312-320.

14. Karkouti K, McCluskey SA, Syed S, Pazaratz C, Poonawala H, et al. (2010) The influence of perioperative coagulation status on postoperative blood loss in complex cardiac surgery: a prospective observational study. Anesth Analg 110(6): 1533-1540.

\section{Your next submission with Juniper Publishers} will reach you the below assets

- Quality Editorial service

- Swift Peer Review

- Reprints availability

- E-prints Service

- Manuscript Podcast for convenient understanding

- Global attainment for your research

- Manuscript accessibility in different formats

( Pdf, E-pub, Full Text, Audio)

- Unceasing customer service

Track the below URL for one-step submission https://juniperpublishers.com/online-submission.php 